\title{
Effectiveness and cost-benefit of an influenza vaccination program for health care workers
}

AnnAleE YAssi, MD, MSC, FRCPC, Joel Kettner, MD, MSC, FRCSC, GREg HAMmOND, MD, FRCPC, MARY ChEANG, MMATH, MYRNA MCGILL, RN

\begin{abstract}
A Yassi, J Kettner, G Hammond, M Cheang, M McGill. Effectiveness and cost-benefit of an influenza vaccination program for health care workers. Can J Infect Dis 1991;2(3):101108. This study retrospectively reviewed the effectiveness of a vaccination program for hospital workers in a large tertiary care hospital, quantified influenza-induced absenteeism, and examined the factors determining the costs and benefits of this program. Absenteeism among high risk hospital workers was increased by $35 \%(\mathrm{P}=0.001)$ during the virulent influenza epidemic of 1987-88. Benefits, measured as the value of sick time avoided, compared with costs, including materials, occupational nursing staff time, employee time during vaccination, and time lost due to adverse reactions, revealed a net benefit of $\$ 39.23$ per vaccinated employee. Sensitivity analyses highlighted vaccine efficacy and absenteeism due to influenza and adverse reactions to vaccination as the most important factors; with time lost due to adverse reactions as much as 0.013 days per vaccinated employee and a vaccine efficacy of $70 \%$, net positive benefits could be achieved if influenza-induced absenteeism is $0.5 \%$ or greater of paid employee time during the epidemic season. The results suggested that the net cost-benefit of a hospital employee vaccination program to decrease both employee morbidity and nosocomial influenza among patients, would be increased by active promotion of the vaccination program, especially for employees in high risk areas.
\end{abstract}

Key Words: Cost-benefit, Hospital workers, Influenza vaccine

\section{Efficacité et rentabilité d'un programme de vaccination antigrippale destiné au personnel de santé}

RESUME: Cette étude rétrospective a examiné l'efficacité d'un programme de vaccination destiné au personnel hospitalier d'un grand établissement de soins tertiaires; elle a quantifié l'absentéisme attribuable à la grippe et examiné les facteurs déterminant les coûts et les bénéfices du programme. Parmi le personnel à haut risque, l'absentéisme a augmenté de $35 \%$ $(\mathrm{P}=0,001)$ au cours de l'épidémie de grippe virulente de 1987-88. Les avantages (valeur de la

Department of Community Health Sciences and Medicine, University of Manitoba: Department Occupational and Environmental Medicine, Health Sciences Centre, Surgery and Family Medicine, Cadham Provincial Laboratory; and Department of Medical Microbiology. Biostatistical Consulting Unit. Winnipeg. Manitoba

Correspondence and reprints: Dr Annalee Yassi, Director, Occupational and Environmental Medicine, Health Sciences Centre. 820 Sherbrook Street. Winnipeg. Manitoba R3A 1R9. Telephone (204) 787-3312, Fax (204) 787-4952

Received for publication October 16, 1990. Accepted February 5, 1991 
période de maladie évitée) mesurés par rapport aux coûts (matériel, temps des infirmières en santé au travail, temps des employés durant la vaccination et heures perdues en raison des effets indésirables) révèlent un bénéfice net de 39,23 \$ par employé vacciné. Les analyses de sensibilité ont montré que l'efficacité du vaccin et l'absentéisme attribué à la grippe et aux effets indésirables de la vaccination constituaient les facteurs les plus importants; avec un nombre de journées perdues pour effets indésirables 0,013 journées par personne vaccinée et une efficacité du vaccin de $70 \%$, on peut obtenir des bénéfices nets quand l'absentéisme dû à la grippe est égal ou supérieur à $0,5 \%$ des journées payées durant la saison épidémique. D’après les résultats, un programme de vaccination destiné au personnel hospitalier diminue à la fois la morbidité parmi le personnel et les infections nosocomiales provoquées par le virus grippal chez les patients; sa rentabilité nette serait majorée par une promotion active - surtout auprès du personnel oeuvrant dans des secteurs à haut risque.

Inementer NFLUENZA CONTINUES TO BE A MAJOR CAUSE OF hospitalization and morbidity among high risk persons $(1,2)$. Influenza A virus infection recurs almost annually, and nosocomial spread of influenza is well known to occur (3-9). Although never unequivocally documented, these outbreaks are thought to be perpetuated by spread of the virus to susceptible hospital staff, who transmit the infection to patients (9). Lost productivity is a major sequela of influenza in healthy adults, with rates of absenteeism among hospital workers of up to $30 \%$ having been noted (7).

The efficacy of influenza vaccine is approximately $70 \%$ in healthy individuals when the vaccine strain matches the epidemic strain (10). It has been suggested that reduced patient morbidity and control of nosocomial outbreaks of influenza could be accomplished by immunization of hospital personnel (9). In order to protect patients who have a high risk of suffering serious complications following influenza infection, vaccination of health care workers who have extensive contact with these patients is recommended (2). However, despite the availability of efficacious vaccines known to be cost effective when administered to high risk patients $(11,12)$, it is widely accepted that the vaccine is underemployed. Immunization of hospital workers may be difficult and less effective once an outbreak has begun (9); this concern highlights the need for intensified efforts prior to each influenza season.

The authors documented increased absenteeism among hospital staff at their institution during the influenza epidemic of 1980-81, and recommended an influenza vaccination program for health care workers (13). Such a program was instituted in 1984, with the influenza vaccine offered to employees annually during the months of October and November by the institution's occupational health department. All health care workers were considered to be at increased risk for acquisition of influenza and were thus offered the vaccination at no cost. Due to the large employee population at this teaching hospital (approximately 5500), only the 800 employees working in areas designated as high risk (by virtue of the patient population and the extent of exposure) (2) received focused teaching and vaccine promotion. These areas (Table 1) were visited twice by an occupational health nurse who posted an information sheet describing the vaccine; her availability to return to answer questions and to administer the vaccine was also discussed with the health care workers present. Individuals were instructed to make their own appointments to receive the vaccine.

The purpose of the present study was: to review acceptance of the existing health care worker vaccination program; to ascertain if excess absenteeism during the influenza season could again be documented; to assess the extent to which influenza season absenteeism was reduced among those vaccinated; and to estimate the cost-benefit of this program, analyzing the factors that most influenced the results.

\section{SUBJECTS AND METHODS}

Employee charts in the occupational health department were reviewed to ascertain the rate of vaccine acceptance for the influenza seasons of 1984-85 to $1988-89$ as a whole and among health care workers designated at increased risk (by virtue of patient population and extent of patient contact, according to the Centers for Disease Control [CDC] guidelines [2]). The extent of ongoing participation in the vaccination program among those vaccinated was also assessed.

The time period of the influenza season was defined by a review of the number and types of influenza strains isolated from specimens (mainly throat swabs) routinely sent from throughout the province to the centralized virus detection laboratory of Cadham Provincial Laboratory 1986-89.

The isolates were identified in the usual manner (13) with reagents provided by the Laboratory Centre for Disease Control (LCDC) in Ottawa; at 
TABLE 1

Number of employees vaccinated and percentage acceptance of influenza vaccine in high risk and non high risk departments 1984-88

\begin{tabular}{|c|c|c|c|c|c|c|c|c|c|c|}
\hline \multirow[b]{2}{*}{ Department } & \multicolumn{2}{|c|}{1984} & \multicolumn{2}{|c|}{1985} & \multicolumn{2}{|c|}{1986} & \multicolumn{2}{|c|}{1987} & \multicolumn{2}{|c|}{1988} \\
\hline & No. & $\%$ & No. & $\%$ & No. & $\%$ & No. & $\%$ & No. & $\%$ \\
\hline \multicolumn{11}{|l|}{ High risk departments } \\
\hline Adult respiratory & 19 & $37 \%$ & 10 & $22 \%$ & 2 & $11 \%$ & 0 & - & 4 & $25 \%$ \\
\hline Adult medicine (three wards) & 36 & $14 \%$ & 43 & $16 \%$ & 58 & $22 \%$ & 16 & $7 \%$ & 13 & $5 \%$ \\
\hline Geriatrics (two wards) & 10 & $17 \%$ & 2 & $3 \%$ & 5 & $9 \%$ & 6 & $12 \%$ & 20 & $38 \%$ \\
\hline Adult ambulatory care/emergency & 8 & $9 \%$ & 7 & $8 \%$ & 4 & $4 \%$ & 12 & $14 \%$ & 7 & $8 \%$ \\
\hline Pediatric intensive care & 0 & - & 2 & $4 \%$ & 6 & $12 \%$ & 10 & $24 \%$ & 5 & $14 \%$ \\
\hline Pediatric surgery & 5 & $21 \%$ & 5 & $23 \%$ & 7 & $25 \%$ & 1 & $3 \%$ & 7 & $18 \%$ \\
\hline Neonatal intensive care & 2 & $5 \%$ & 0 & - & 1 & $1 \%$ & 1 & $1 \%$ & 0 & - \\
\hline Total from high risk departments & 80 & $11 \%$ & 69 & $9 \%$ & 85 & $10 \%$ & 50 & $6 \%$ & 57 & $7 \%$ \\
\hline Non high risk departments & 9 & & 16 & & 61 & & 42 & & 55 & \\
\hline
\end{tabular}

least one isolate was sent annually for reference typing to the LCDC and to the CDC in Atlanta, Georgia. In 1986-87 there were only three isolates of influenza A virus (influenza A/Taiwan/1/86like virus $[\mathrm{H} 1 \mathrm{~N} 1])$ documented. In contrast, 12 isolates of influenza A/Sichuan/2/87-like virus (H3N2) and 29 isolates of influenza B intermediate between influenza B/Ann Arbor/1/86-like virus and $\mathrm{B} /$ Victoria/2/87-like virus were documented between January 1 and March 24, 1988 (Figure 1). From within the authors' institution there was no influenza isolate in 1986-87, compared to 14 isolated from participants and staff in the 1987-88 season (five influenza A and nine influenza B). There was, therefore, only a partial match between the vaccine offered in the autumn of 1987 (which contained influenza A/Leningrad/360/86 and B/Ann Arbor/1/86) and the strains of influenza virus isolated from persons in the hospital and the community in the 1987-88 winter season.

Records for 1986-88 were available to ascertain absenteeism rates (hours lost due to sickness per hours paid). The 1987-88 year was chosen as the focus of study. The rate of hours lost per hours paid in the 14 week period during the influenza season was compared to the eight week period before the outbreak, the eight weeks after the outbreak, and the rest of the calendar year. With few isolates and no significant morbidity in the community during the 1986-87 winter season, this year was used as a 'comparison' year (Figure 1).

Of the 92 persons who received the vaccine in the fall of 1987, 52 were employed in areas considered to be at high risk for acquisition of influenza. Of these 52, pre-vaccination absenteeism data were available for all but two employees; similarly, post vaccination data were available for all but two

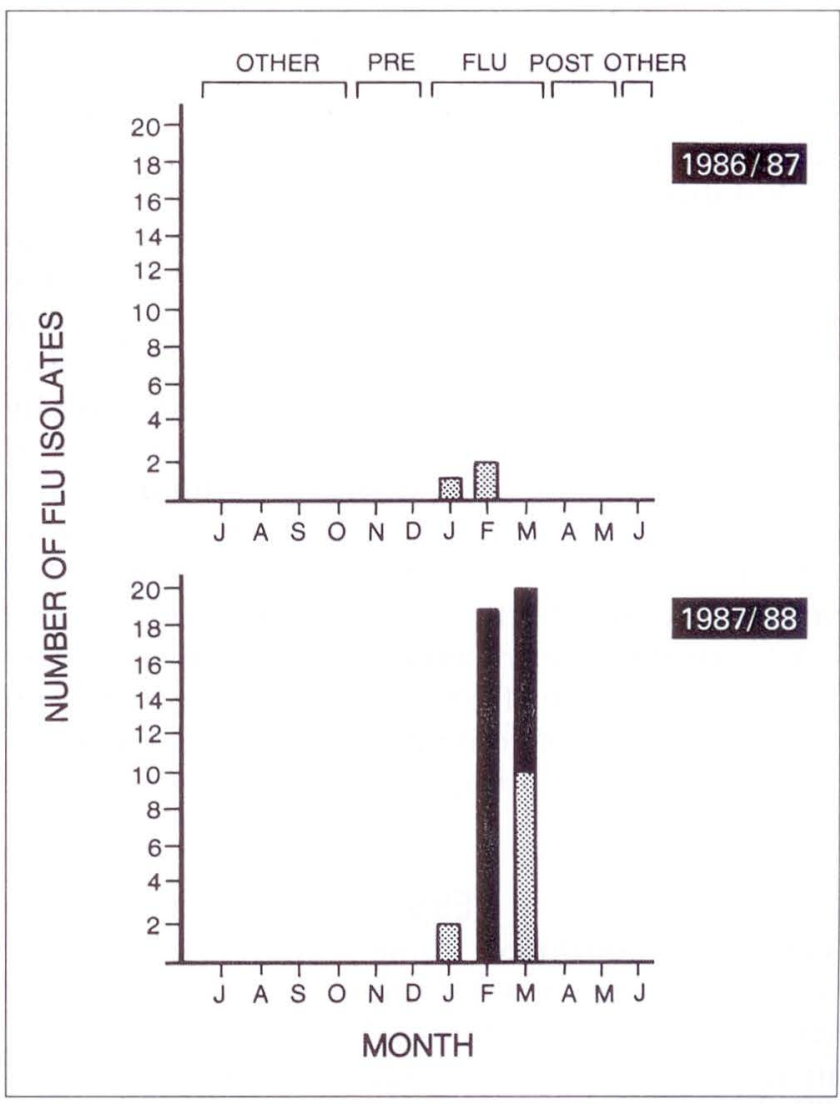

Figure 1) Influenza isolates by month July 1986 to June 1988 with designated 'flu' and comparison study periods. Stippled bars Isolates of influenza A: Solid bars Isolates of influenza $B$

employees. Absenteeism data were therefore collected on 48 vaccinated high risk health care workers for both the 1986-87 season ('comparison year') and for the 'flu' and 'non-flu' periods in the 1987-88 season. Their demographic and risk factor profiles were compared with a random sample 
of other employees in their departments who did not receive the vaccine $(n=139)$.

Absenteeism data were analyzed using a randomized block design analysis of variance to determine the significance of variation in rates. Demographic profile data were analyzed using $\chi^{2}$ and $t$ tests as appropriate.

The cost-benefit analysis was limited to consideration of work time lost related to influenza and/or the prevention program in addition to the direct costs of the program. Positive and negative outcomes which did not affect time lost from work were not considered. Thus, the important reason for vaccinating health care workers, ie, the potential benefit to hospital patients through reduction of nosocomial infection and its complications, was not considered, nor was the cost associated with responding to influenza outbreaks. Because the vaccination program was a small 'add on' to the activities of the occupational health department, overhead and capital costs were not considered. Discounting of costs and benefits was not necessary, as they were accrued within the year of vaccination.

Benefits of the influenza vaccination program were measured as the dollar value of sick time avoided by the prevention of influenza, estimated from the absenteeism data. The costs of the vaccination program included: cost of time lost by recipients due to vaccination, and material and labour costs associated with the promotion and administration of the vaccine. Time lost due to adverse reactions was estimated from information voluntarily reported to the occupational health clinic, and thus represented a minimum estimate. The average value of labour time was derived from the salary scale of general duty nurses, who comprise the largest group of high risk health care workers.

\section{RESULTS}

Vaccine acceptance: Table 1 shows the number and proportion of total employees who received vaccine in high risk and non high risk departments in each year of the program. Results show that acceptance rates were low (6 to $11 \%$ per year) and showed no consistent trend. The highest proportion of vaccine acceptance in any ward was $43 \%$, which occurred in 1988 on one of the geriatric nursing wards. Further analyses revealed that the same individuals did not consistently receive vaccine each year. For example, of the 146 employees vaccinated in 1986, 120 were first time vaccinees; only 26 of those vaccinated in 1986 were also vaccinated in 1987. Of the 92 vaccinated in 1987 , 64 were first time vaccinees, 23 were second timers, three were third timers and only two had
TABLE 2

Absenteeism rates for employees in high risk departments

\begin{tabular}{|c|c|c|c|c|c|c|}
\hline & \multicolumn{6}{|c|}{ Absenteeism rates * } \\
\hline & $\begin{array}{l}\text { Influenza } \\
\text { outbreak }\end{array}$ & \multicolumn{2}{|c|}{$\begin{array}{l}\text { Outbreak } \\
\text { season }\end{array}$} & \multicolumn{2}{|c|}{ Other seasons } & \multirow{2}{*}{$\begin{array}{c}\mathrm{P} \\
\mathrm{NS}\end{array}$} \\
\hline \multirow[t]{3}{*}{$1986-87$} & No & 0.038 & versus & pre-'flu': & 0.044 & \\
\hline & & & & post 'flu': & 0.036 & NS \\
\hline & & & & all other: & 0.034 & NS \\
\hline \multirow[t]{3}{*}{$1987-88$} & Yes & 0.049 & versus & pre-'flu': & 0.037 & 0.003 \\
\hline & & & & post 'flu': & 0.036 & 0.001 \\
\hline & & & & all other: & 0.037 & 0.002 \\
\hline
\end{tabular}

"Absenteeism was expressed as the number of hours lost per numbers of hours paid. NS Not significant

received vaccine in all four years of the program. The maximum proportion of repeat vaccinees was $41 \%$, which occurred in 1988; only $11 \%$ of the 112 employees vaccinated that year received vaccine for three or more consecutive years. With an annual staff turnover of less than 5\% in this group of health care workers, the attrition rate from the vaccination program is quite high.

Absenteeism during influenza epidemics: As shown in Table 2 , there was a significant difference between absenteeism rates during the 1987-88 influenza season and the three noninfluenza periods in that year, with an absenteeism rate approximately 35\% higher than either the pre-influenza, post influenza or remaining periods of the year. During the corresponding calendar period of the previous year, in which no influenza epidemic occurred, no increase in absenteeism occurred.

The increase in absenteeism for employees of other areas of the hospital was not as great as among the 800 health care workers in high risk patient care areas during the influenza epidemic of 1987-88, with an insignificant increase in absenteeism during the outbreak $(0.034$ hours absent per hour paid versus 0.032 prior to the outbreak, 0.027 after the outbreak, and 0.025 in all other periods of that year). Also, while the absenteeism rate among non high risk employees during the 1987-88 influenza season was higher than during the same calendar period in the previous year, the difference was not statistically significant.

The vaccinated group: An analysis was conducted to assess if the 48 high risk employees who were vaccinated escaped the increase in absenteeism documented for the high risk departments during the 1987-88 influenza season. The data revealed no significant difference in absenteeism between outbreak and nonoutbreak seasons in this group $(0.037$ during the outbreak versus 0.035 prior to or 0.24 post outbreak). Although the numbers were too small to allow firm conclusions 
TABLE 3

Best estimate of benefits and costs per vaccinated employee

\begin{tabular}{|c|c|}
\hline \multicolumn{2}{|l|}{ Benefit } \\
\hline $\begin{array}{l}\text { 0.7\% reduction in absenteeism during } 14 \text { week period } \\
(3.8 \mathrm{~h} \text { per vaccinated employee at } \$ 15.72 / \mathrm{h} \text { ) }\end{array}$ & $\$ 59.70$ \\
\hline Total & $\$ 59.70$ \\
\hline \multicolumn{2}{|l|}{ Costs } \\
\hline \multicolumn{2}{|l|}{ Vaccine materials } \\
\hline Vaccine & $\$ 2.25$ \\
\hline Syringe needle, etc & 0.25 \\
\hline Promotion time of occupational nurse $(0.3 \mathrm{~h} \times \$ 17.60)$ & 5.27 \\
\hline $\begin{array}{l}\text { Administration of vaccine by occupational nurse } \\
(1 / 3 \mathrm{~h} \times \$ 17.60)\end{array}$ & 5.87 \\
\hline \multicolumn{2}{|l|}{ Average time lost by vaccinated employee } \\
\hline During administration $(0.33 \mathrm{~h} \times \$ 15.71)$ & 5.25 \\
\hline Due to adverse reaction ( 0.013 day $\times 7.75 \mathrm{~h} \times \$ 15.71)$ & 1.58 \\
\hline Total & 20.47 \\
\hline Net benefit per vaccinated employee & 39.23 \\
\hline
\end{tabular}

The model assumes that $10 \%$ of employees were vaccinated

(63\% power to detect a 0.01 drop in absenteeism rate, alpha $=0.05$, one-tailed), it is noteworthy that the rate of absenteeism among those vaccinated was lower during the 1987-88 influenza season (0.037) than for the corresponding period in the previous year (0.046) when no influenza outbreak was documented.

It was found that vaccinated health care workers did not differ significantly from others in their departments by gender $(95 \%$ versus $97.1 \%$ female), marital status (62.5\% versus $55.4 \%$ married), number of children at home (0.9 versus 1.3 ), or history of relevant chronic diseases, although the vaccinated group was slightly older (mean age 37.2 versus 34.2 years, $\mathrm{P}=0.044$ ).

Benefits and costs: Estimates of benefits and cost per vaccinated employee (based on the 1987-88 influenza season data) are shown in Table 3. Employees in high risk departments had a $4.9 \%$ absenteeism rate during the 1987-88 influenza period ( 14 weeks) compared with $3.7 \%$ throughout the rest of the 1987-88 year, and 3.8\% during the corresponding 14 week period in 1986-87 when there was no influenza outbreak. Thus it was estimated that absenteeism could have been reduced by approximately $1 \%$ (4.9\% to $3.8 \%$ ) during the 1987-88 influenza period had influenza been completely prevented. At a vaccine efficacy of $70 \%$, each employee vaccinated would be expected to reduce his or her sick time by $0.70 \%(1 \% \times 0.70)$ of the total time worked during the 14 week 'flu period'. At $38.75 \mathrm{~h} /$ week per employee, the estimated time of sickness saved per vaccinated employee is $38.75 \mathrm{~h}$ /week $\times 14$ weeks $\times 0.007$ (absenteeism reduction) $=3.8 \mathrm{~h}$. At an average pay value of $\$ 15.72 / \mathrm{h}$ (for a general duty nurse II with three years of seniority), this represents an average expected benefit of $\$ 59.70$ (3.8 h $\times \$ 15.72 / \mathrm{h})$ per vaccinated employee.

Direct costs associated with vaccine administration included costs of materials for each vaccination, $(\$ 2.25$ for the vaccine and $\$ 0.25$ for the needle, syringe, swabs, etc) totaling $\$ 2.50$, as well as an estimated 20 mins of the occupational health nurse's time for each vaccinated employee (including preparation, travel within the hospital, charting and filing), representing a cost of $\$ 5.87$ $(1 / 3 \mathrm{~h} \times \$ 17.60 / \mathrm{h})$ per vaccinated employee. The only fixed annual cost of the program considered was that of the two promotion visits by the occupational health nurse to the 32 high risk wards. The estimated total time spent to promote the program was 45 mins per ward, or $24 \mathrm{~h}$ total. At $\$ 17.60 / \mathrm{h}$, the cost of the occupational nurse's time was $\$ 422.00$, or $\$ 5.27$ per vaccinated employee.

At an estimated 20 mins lost from work duties for the recipient for the vaccination process (travel from work assignment, completion of brief health questionnaire, interview, informed consent and vaccination), the cost component of vaccine administration was estimated at \$5.25 (1/3 hx $\$ 15.716 / \mathrm{h})$ per vaccinated employee. Of 412 employees receiving the vaccine during 1984-87, 32 reported adverse reactions resulting in a total of 22 days off work. Using these data, 0.05 (22/412) days were lost following vaccination. This is the same post vaccination absenteeism rate recently reported from a hospital employee influenza vaccination program in Vancouver (14). Thus the lost time attributable to adverse vaccine reaction is 0.013 days $(0.05-0.037$ baseline days in the pre-influenza period) resulting in a cost of $\$ 1.58(0.013$ days $\times 7.75 \mathrm{~h} \times \$ 15.716 / \mathrm{h})$ per vaccinated employee.

Cost-benefit analysis: As shown in Table 3, at an acceptance rate of $10 \%$, the benefits and costs per vaccinated employee are $\$ 59.70$ and $\$ 20.47$, respectively, for a net benefit of $\$ 39.23$ (appendix 1 for cost-benefit formula). If all 800 employees in the designated high risk areas were given the influenza vaccine (ie, 100\% acceptance) with no change in promotion costs, the net benefit per vaccinated employee would be $\$ 43.98$, yielding a total benefit of $\$ 35,182.59$.

Sensitivity analyses of the variable cost components show that net savings per vaccinated employee could fall from $\$ 39.23$ to $\$ 9.38$ if only one-half of the excess influenza season absenteeism were prevented by vaccination or if absenteeism reduction of this magnitude occurred every other year (Table 4). Alternatively, it would rise to $\$ 47.75$ if vaccine efficacy were increased from 70 
TABLE 4

Univariate sensitivity analyses of major benefits and cost determinants

\begin{tabular}{|c|c|c|c|c|}
\hline & $\begin{array}{c}\text { Best } \\
\text { estimate }\end{array}$ & $\begin{array}{l}\text { Other } \\
\text { estimates }\end{array}$ & $\begin{array}{c}\text { Net benefit per vaccinated employee } \\
\text { (at 10\% acceptance rate) }\end{array}$ & $\begin{array}{l}\text { Total net benefit for } 800 \text { vaccinated } \\
\text { employees ( } 100 \% \text { acceptance) }\end{array}$ \\
\hline \multicolumn{5}{|c|}{ Benefits - sick time saved at $\$ 15.76 / \mathrm{h}$} \\
\hline \multirow{3}{*}{$\begin{array}{l}\text { Absenteeism rate } \\
\text { due to influenza }\end{array}$} & $1.0 \%$ & & $\$ 39.23$ & $\$ 35,182.59$ \\
\hline & & $0.50 \%$ & 9.38 & $11,303.91$ \\
\hline & & $0.25 \%$ & -5.55 & -635.43 \\
\hline Vaccine efficacy & & $60 \%$ & 30.70 & $28,360.11$ \\
\hline \multicolumn{5}{|l|}{ Costs } \\
\hline \multirow[t]{3}{*}{ Vaccine materials } & @ $\$ 2.50$ & & 39.23 & $35,182.59$ \\
\hline & & (a) $\$ 5$ & 36.73 & 33.182 .59 \\
\hline & & @ $\$ 10$ & 31.73 & 29.182 .59 \\
\hline \multirow{3}{*}{$\begin{array}{l}\text { Time lost due to } \\
\text { adverse reaction }\end{array}$} & & 0.005 days & 40.20 & $35,962.31$ \\
\hline & & 0.05 days & 34.72 & 31.576 .43 \\
\hline & & 0.10 days & 28.63 & 26.703 .23 \\
\hline
\end{tabular}

TABLE 5

Three-way sensitivity analyses of net benefits per vaccinated employee

\begin{tabular}{|c|c|c|c|c|c|c|}
\hline \multirow{2}{*}{$\begin{array}{l}\text { Absenteeism } \\
\text { due to influenza } \\
\text { (days) }\end{array}$} & \multicolumn{3}{|c|}{$\begin{array}{c}0.2 \text { days }^{*} \text { lost due to adverse reaction } \\
\text { Vaccine efficacy }\end{array}$} & \multicolumn{3}{|c|}{$\begin{array}{c}0.013 \text { days }{ }^{\star} \text { lost due to adverse reaction } \\
\text { Vaccine efficacy }\end{array}$} \\
\hline & $60 \%$ & $70 \%$ & $80 \%$ & $60 \%$ & $70 \%$ & $80 \%$ \\
\hline 0.01 & 7.92 & 16.44 & 24.97 & 30.70 & 39.23 & 47.75 \\
\hline 0.0075 & -4.88 & 0.52 & 7.92 & 10.16 & 16.55 & 22.95 \\
\hline 0.005 & -17.67 & -13.40 & 9.14 & -2.64 & 1.63 & 5.89 \\
\hline 0.0025 & -30.46 & -28.33 & -26.20 & -15.43 & -13.30 & -11.16 \\
\hline
\end{tabular}

- Per vaccinated employee

\section{TABLE 6}

Two-way sensitivity analysis of net benefits per vaccinated employee and total program net benefit for a study of vaccination acceptance rates among 800 high risk health care workers

\begin{tabular}{|c|c|c|c|c|c|c|c|}
\hline & & \multicolumn{2}{|c|}{$10 \%$ acceptance } & \multicolumn{2}{|c|}{$50 \%$ acceptance } & \multicolumn{2}{|c|}{$100 \%$ acceptance } \\
\hline & & Per employee* & Total $^{\dagger}$ & Per employee* & Total $^{\dagger}$ & Per employee* & Total $^{\dagger}$ \\
\hline Costs of program & $\$ 422$ & $\$ 39.23$ & $\$ 3138.10$ & $\$ 43.45$ & $\$ 17,380.10$ & $\$ 43.98$ & $\$ 35,182.59$ \\
\hline Promotion $\quad(x 5)$ & $\$ 2112$ & $\$ 18.11$ & $\$ 1448.50$ & $\$ 39.23$ & $\$ 15,690.50$ & $\$ 41.87$ & $\$ 33,492,99$ \\
\hline$(x 10)$ & $\$ 4220$ & $-\$ 8.29$ & $-\$ 663.50$ & $\$ 33.95$ & $\$ 13,578.50$ & $\$ 39.23$ & $\$ 31,380,99$ \\
\hline
\end{tabular}

"Net benefit per vaccinated employee. ${ }^{\dagger}$ Total program net benefit

to $80 \%$. Even if $20 \%$ of vaccinated employees experienced an adverse reaction resulting in one day lost from work, there would still be a net benefit of $\$ 16.44$ per vaccinated employee.

The variables which impact most on the costbenefit analysis are: estimated absenteeism due to influenza, the efficacy of the vaccine, estimated absenteeism due to adverse reactions to the vaccine, acceptance rate, and promotion costs.

A three-way sensitivity analysis shows that if time lost due to adverse reactions is as low as 0.013 days, net positive benefits can be achieved at all but the lowest estimates of rates of influenza absenteeism and vaccine efficacy (Table 5). Even if time lost due to adverse reactions were as high as 0.02 days per vaccinated employee $(20 \%$ of vaccinations, one day per adverse vaccination), net positive benefits could be achieved with vaccine efficacy in the range of 60 to $80 \%$ if the increase in absenteeism rate due to influenza is $1.00 \%$.

Another sensitivity analysis indicates that even large increases in the cost of promotion would be worthwhile, if improved acceptance could be 
achieved (Table 6). Thus, if spending 10 times the rate $(\$ 4220)$ on promotion resulted in a fivefold increase in acceptance (from 10 to $50 \%$ ), the net benefit per vaccinated employee would fall from $\$ 39.23$ to $\$ 33.95$, but the total net benefit would rise from $\$ 3138.00$ to $\$ 15,690.50$, because a larger number of employees would be vaccinated.

\section{DISCUSSION}

This study was conducted to provide information which would assist in the formulation of policy for influenza vaccination of hospital employees, and specifically to determine whether vaccination of health care workers at high risk of acquiring influenza because of the type of patients they work with and the extent of exposure to these patients, will result in net savings to hospitals by reducing costs associated with employee absenteeism. In the absence of a controlled trial to demonstrate the effectiveness of reducing hospital employee absenteeism by influenza vaccination, the potential benefits can only be estimated indirectly - as in this study - using retrospective data. The magnitude of the increase in absenteeism during the 1987-88 influenza season compared to prior to the 'flu outbreak, after the outbreak, or at other times of the year, was approximately $35 \%$. While the vaccinated group was small, the absenteeism rate for vaccinated health care workers working in high risk areas was considerably lower than the overall rate in their departments. The estimates of the reduction in absenteeism among vaccinated employees are most likely lower than what could be expected during an epidemic for which there was a better match of vaccine to actual influenza strains.

Estimates from available data indicated a $\$ 39.23$ net benefit per vaccinated employee in the influenza epidemic year studied. If all $800 \mathrm{em}-$ ployees in the designated high risk areas had been vaccinated (with no change in program costs), a total net benefit of $\$ 35,182.59$ could have been realized that year. Because the value of 'unused' sick time is not returned to the employee, and if replacement nurses are hired to staff the wards affected by absenteeism, the calculated net benefit value could represent a true cost saving.

Aside from the potential benefit to the hospital and the community, the reduced absenteeism suggested by these data likely indicates reduced morbidity for vaccinated employees. Despite the high prevalence of minor vaccine side effects reported elsewhere (14), this result should still represent a net benefit to the employee.

Moreover, a health care worker vaccination program holds potential for reduced nosocomial in- fluenza in hospital patients. (This latter benefit may be a more important consideration than the potential cost savings from employee absenteeism alone, and vaccination of health care workers could be justified even if the vaccination program had a net cost.)

Employees without direct patient contact (ie, working in non high risk areas) had a slightly elevated absenteeism rate during the 1987-88 influenza season. However, it was not significantly higher than during the pre-influenza period, and was only a borderline increase in comparison with the post influenza period and other periods of the year. This finding suggests that prevention of influenza infection among hospital staff can be made more efficient by selective targeting of preventive strategies towards high risk health care workers who, in any case, are more important to target with respect to decreasing potential for nosocomial spread.

In the future, targeting of preventive strategies among hospital staff (vaccine and/or antiviral drugs) may also be more selective if timely surveillance programs could indicate whether a virulent subtype is likely to be circulating in the community that year. For example, retrospective observations of ongoing surveillance in the United States indicate that since 1968-69, the highest excess mortality due to pneumonia and influenza has been associated with influenza A/H3N2 viruses (15), suggesting increased virulence. The observation of excess staff absenteeism in the authors' institution in the influenza seasons of 1980-81 (13) and in 1987-88 (present study), when influenza A/H3N2 viruses were predominant, is consistent with this concept, although influenza B was also detected in the latter influenza period. It is also noted that the efficacy of the vaccine, influenced by the degree of match between influenza strain and vaccine, affects the cost-benefit of the program. For the present, hospitals should plan for annual vaccination programs, as influenza epidemics and virulence cannot be predicted with accuracy.

Despite the availability of free influenza vaccine, an average of less than $10 \%$ of health care workers in high risk areas accepted vaccine in any of the years of the program; at most only $41 \%$ were repeat vaccinees, and never more than $11 \%$ of those vaccinated received vaccine in more than two consecutive years. The data indicate both low acceptance rates and high attrition rates for the current program. The manner in which the program is delivered and, particularly, the extent of its promotion, clearly play a role. Schiefele and colleagues (14) reported an acceptance rate greater than 50\% among hospital employees. 


\title{
APPENDIX 1

(Absenteeism rate due to influenza) x (Vaccine efficacy) x ('Flu period in weeks) x (Hours worked per week) x (Average hourly wage of VE)

SUBTRACT

\author{
((Hours lost due to adverse reaction) + (Hours lost during vaccination)) $x$ (Average hourly wage of VE) \\ + ((Hours spent by OHN per VE) + (Hours spent by OHN to promote program per VE)) $x$ (Average hourly wage of OHN) \\ + (Cost of each vaccine) + (Cost of other materials per vaccination)
}

OHN Occupational health nurse: VE Vaccinated employee

Their methods of promotion included not only general notices but also individual memos and information meetings. Other health care worker vaccination programs suggest greater efficiency by using mobile vaccination carts to decrease time lost related to vaccine administration (personal communication) and Nichol et al (16) illustrated

\section{REFERENCES}

1. Fedson DS. Influenza and pneumococcal immunization strategies for physicians. Chest 1987;91:436-43.

2. ACIP. Prevention and control of influenza: Recommendations of the Immunization Practices Advisory Committee. MMWR 1990;39:1-15.

3. Kapila R, Lintz DI, Tecson FT, et al. A nosocomial outbreak of influenza A. Chest 1977;71:576-9.

4. Bauer CR, Elie K, Spence L, et al. Hong Kong influenza in a neonatal unit. JAMA 1973;233:1233-5.

5. McDougal BA, Hodges GR, Lewis HD, et al. Nosocomial influenza A infection. South Med J 1977;70:1023-4.

6. Meibalane R, Sedmak GV, Sasidharan P, et al. Outbreak of influenza in a neonatal intensive care unit. J Pediatr 1977;91:974-6.

7. O’Donoghue JM, Ray CG, Terry DW, et al. Prevention of nosocomial influenza infection with amantadine. Am J Epidemiol 1973;97:276-82.

8. Van Voris LP, Belshe RB, Shaffer JL. Nosocomial influenza B virus infection in the elderly. Ann Intern Med 1982;96:153-8.

9. Pachucki C, Walsh Pappas SA, Fuller GF, et al. that promotion of an institution-wide patient vaccination program can be very effective. The total net benefits of the vaccination program at the authors' institution could be increased substantially if improvements in program design and implementation resulted in higher rates of employee vaccination.

Influenza A among hospital personnel and patients. Arch Intern Med 1989; 148:77-80.

10. Ruben FL. Prevention and control of influenza: Role of vaccine. Am J Med 1987;82(Suppl 6A):31-4.

11. Schoenbaum SC. Economic impact of influenza The individual's perspectives. Am J Med 1987;82(Suppl 6A):26-30.

12. Riddiough MA, Sisk JE, Bell JC. Influenza vaccination - Cost-effectiveness and public policy. JAMA 1983;249:3189-95.

13. Hammond GW, Cheang M. Absenteeism among hospital staff during an influenza epidemic; Implications of immunoprophylaxis. Can Med Assoc J 1984;131:449-52.

14. Schiefele DW, Bjornson G, Johnston J. Evaluation of adverse events after influenza vaccination in hospital personnel. Can Med Assoc J 1990; 142:127-30.

15. Epidemiologic notes and reports, influenza United States. MMWR 1988;37:207-9.

16. Nicol KL, Korn JE, Margolis KL, Poland ZA, Petzel RA, Lofgren RP. Achieving the national health objective for influenza immunization: Success of an institution-wide vaccination program. Am J Med 1990;89:156-60. 


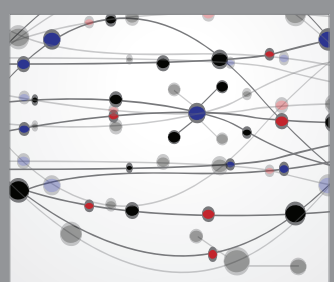

The Scientific World Journal
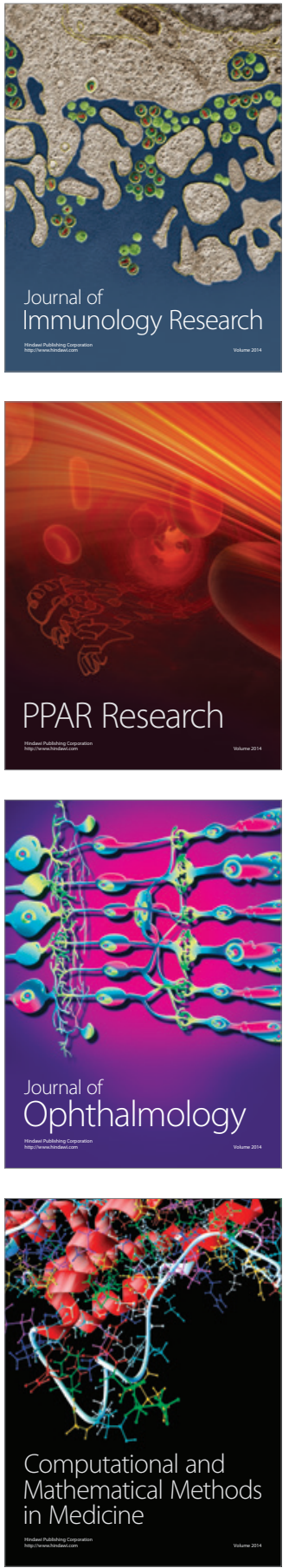

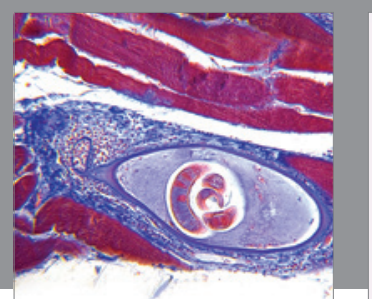

Gastroenterology Research and Practice

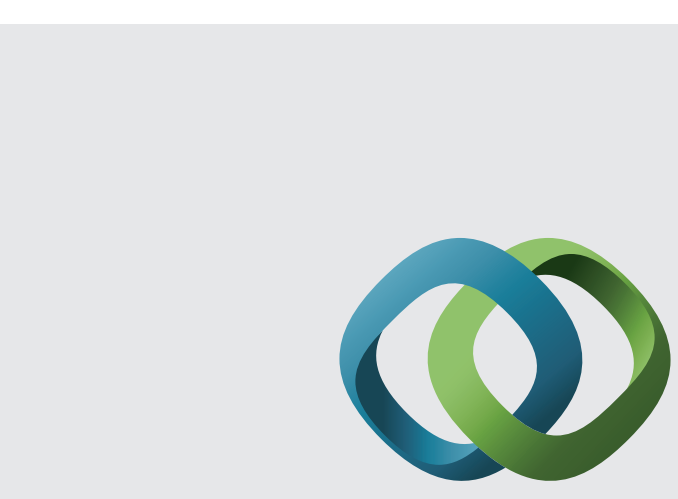

\section{Hindawi}

Submit your manuscripts at

http://www.hindawi.com
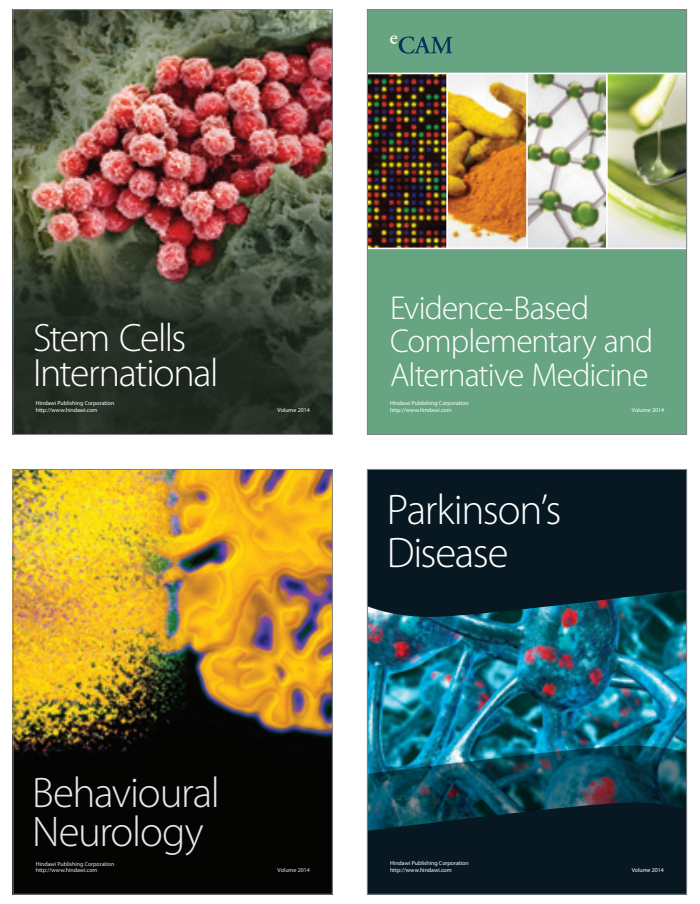
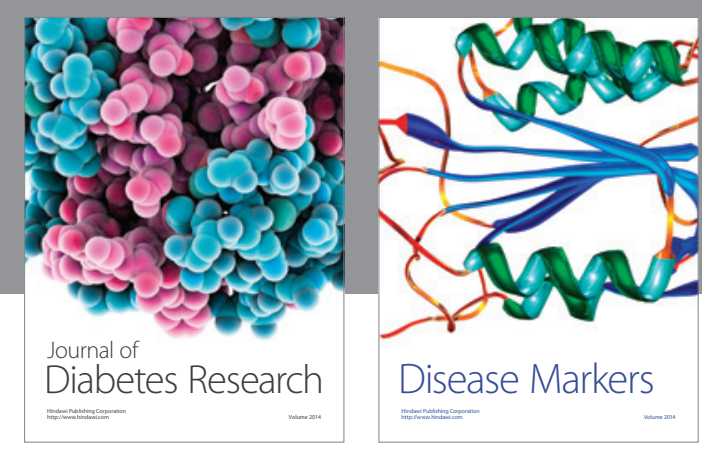

Disease Markers
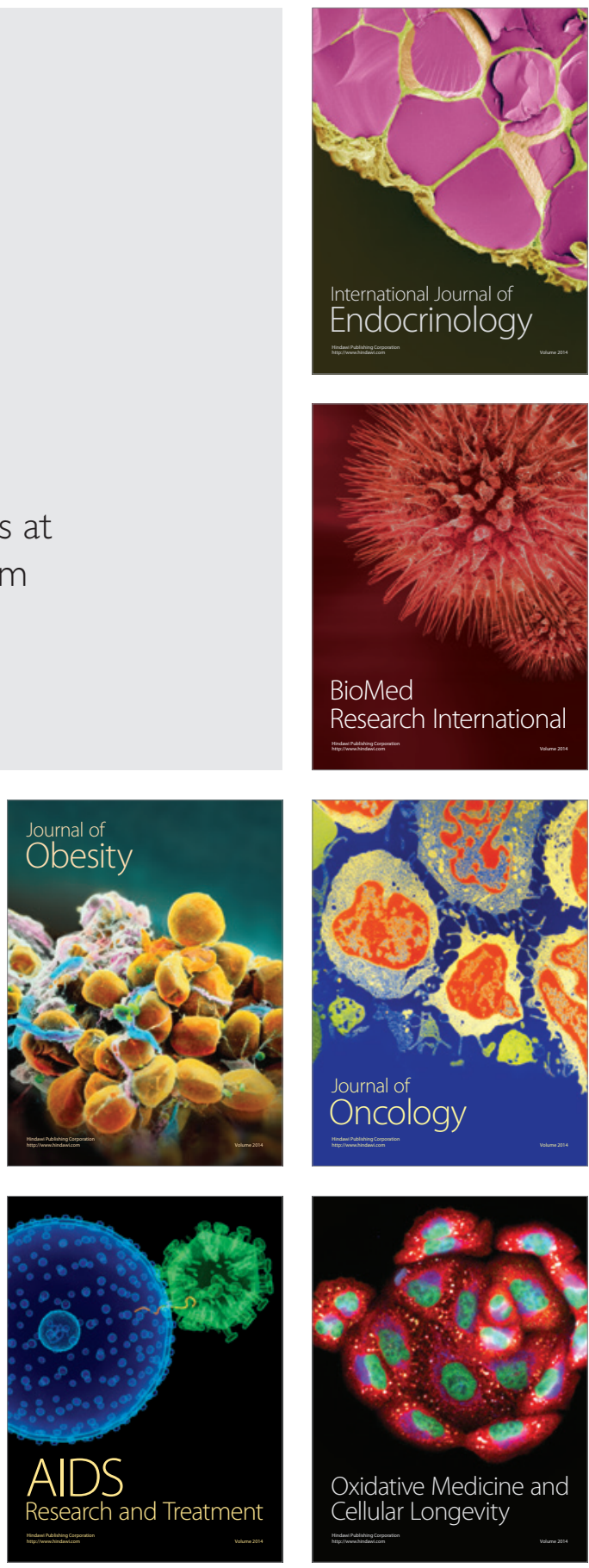